would enable a united profession to use its persuasive powers rightly to convince the Review Body of the justice of our case for adequate payment in respect of the enormous load that doctors in all branches of the profession carry in supporting the National Health Service.

GORDON W TAYLOR

Reading

\section{Anaesthetists' manpower and staffing}

SIR,-The recent report from the Association of Anaesthetists' working party on manpower and staffing of anaesthetists ${ }^{1}$ is important reading and has wide implications for those in that discipline. Based on a 17-district survey in 1974 , it includes comments by consultants on the working of juniors which reveal a typical lack of interest in the on-call commitment of juniors, and it has equally important implications for all those involved in emergency care of patients.

The report was mainly concerned with consultants' work load and there was a hiatus of information about emergency care, which led to an erroneous statement in the conclusions to the effect that any reduction of juniors' working hours might result in insufficient experience in their training, particularly in emergency care. The report, which was conspicuously produced by consultants, failed to analyse the actual work performed by juniors outside the basic working week. As in other specialties, it is probably true to say that the great majority of this work is performed by the SHO and registrar grades and that in most hospitals the exposure to emergency medicine is more than adequate. With notable exceptions it is equally true to say that consultants are very rarely called in to witness these afterhours activities and are consequently underestimating the on-call work load. Perhaps if the new consultant contract prices a recall fee at an attractive level juniors will witness greater consultant interest in emergency anaesthesia. This is not likely to be a popular view, but juniors connected with sterilisation procedures know only too well how the separate attractive fee has made sterilisation for the most part a consultant's operation.

To be constructive about on-call commitments it is important to reduce the actua hours worked each week to well below the 80 hours which are the current average for $\mathrm{SHO}$ anaesthetists. Fatigue is still a major problem in juniors' on-call duties and emergencies would receive better attention if this dangerous element of medicine were to be eliminated. Juniors in all specialties should be careful to submit their own evidence to any reports on manpower and staffing. For the large bulk of training jobs shorter working hours would still give ample experience in emergency medicine without a need to increase further the period required for training.

ADRIAN ROGERS

Exeter

1 Report of a Working Party on Manpower and Staffing,
Association of Anaesthetists of Great Britain and Association of
Ireland, 1978.

\section{Pathologists' work load}

SIR,-It is freely acknowledged that the work load in National Health Service pathology laboratories has increased by about $10 \%$ per annum since 1948. Nevertheless, I have not heard of this staggering example of increased productivity being used as a negotiating lever in evidence to the Review Body, nor has there ever been the slightest suggestion of gratitude or thanks by the DHSS for this massive contribution to the efficient running of the National Health Service in all our meetings with the Department. In many laboratories it has proved impossible to increase the consultant establishment because of inadequate facilities and accommodation, even in new laboratories built to the specifications of the current Hospital Building Note 15-which, despite protestations, has remained basically unaltered since 1962

A considerable proportion of this increased work has come from specimens sent in by general practitioners, and yet this is something which has not been properly discussed with, or agreed by, the profession. I doubt if any consultant pathologist has, as part of his contract, a specific undertaking to examine specimens from general practitioners. I have nothing to this effect in my contract and nothing of this nature was mentioned when I took up my post. In fact, no work for general practitioners was done in my laboratory. However, in an attempt to assist them and their patients, and because there seemed to be some difficulty in obtaining and preparing proper syringes and other equipment, and also to foster a spirit of good will and co-operation, facilities were gradually offered to general practitioners, largely on an "old boy" basis. This has been allowed to grow out of all proportion to the facilities which are, and should be, available in hospital laboratories. This has naturally been encouraged by the DHSS, which seems to have little idea of what a consultant pathology service really is, until it is now, apparently, considered to be a service on demand. This is a new concept in the National Health Service, which cannot yet have reached the kidney sufferers of Hammersmith Hospital-although since they are only a temporary voting minority lacking in "political muscle" this is scarcely surprising.

The DHSS has abandoned the principle stated in $\operatorname{HM}(70) 50$, where it is considered that any pathology service for general practitioner patients is provided "to ease the load of the hospital service" and to enable patients to be treated at home. The hospital pathology service is now apparently considered to be an endless piece of elastic open to all and sundry, although, of course, only receiving the same proportion of financial increases as those allotted to other hospital services.

Fortunately, the BMA has recognised the difficulties some consultants might find themselves in and has attempted to limit these incursions into a consultant's time, with some success in respect of the Employment Medical Advisory Service and the family planning services. Nevertheless, there are often hidden and, at first, unrecognised increases in a consultant pathologist's work load which occur as a result of changing policies and attitudes resulting from the permissive society. One of the results of the free distribution of contraceptives has been the remarkable increase in the demand for pregnancy tests. Some of these tests justify a fee under the family planning agreement but the majority do not; and yet it is obvious that in a large proportion of these cases the patient has not been clinically examined and the test is often irresponsible, for trivial reasons, and unnecessary, and has been asked for on what might be euphemistically interpreted as "social grounds" only. In addition, many of these tests have legal implications. Representatives of the general practitioners have recently stated that they consider that these tests should be available under the National Health Service but that they should be paid for. It is hoped that the BMA will urgently pursue this idea.

Looking at the question of the examination of specimens from general practitioners as a whole, we consider that a consultant pathologist has exactly the same contract as other consultants and that it is composed of two parts. The first is the examination of National Health Service patients who are properly registered as inpatients and outpatients of the hospital at which the consultant has a contract, and the second is the provision of a domiciliary service by means of domiciliary vists. In our opinion the examination of general practitioner specimens is clearly part of a domiciliary service-in fact, it could be considered to be the most efficient and comprehensive domiciliary service offered by the National Health Service. However, by giving this service the consultant pathologists are clearly pre-empting themselves from doing domiciliary visits and receiving payment for them. We consider therefore that the provision of a laboratory service for general practitioners, as at present conducted, should be separately rewarded and we hope that the BMA will press for this. If the BMA is unsuccessful in this, however, the introduction of the new contract will allow all the work commitments by consultants to be reconsidered. This will therefore be a time to look at work outside a consultant's normal hospital commitments and to ask for extra sessions to cover additional work. It is to be hoped that the BMA will develop a common policy to cover a pathologist's work from specimens sent in by general practitioners. Otherwise it would seem appropriate that the so-called "open access" should now be brought to a close.

G S ANDREWS Chairman, BMA's Consulting

Royal Gwent Hospital,
Newport, Gwent

\section{Points}

\section{An objectionable application form}

Dr H G Easton (Glasgow) writes: In the application form supplied by the Lanarkshire Health Board the candidate is asked to give details of any present or past disability. I suggest that, though a candidate may properly be asked to trust in a doctor delegated to determine his fitness, it is surely wrong to circulate confidential medical information among the appointment committee. Health authorities should set an example to other employers not only in health promotion but also in ethics.

\section{Treatment of accidental hypothermia}

Dr M C MACINNES (leader, Glenelg Mountain Rescue Team) writes: Further to the letter of Drs P J Andrew and R S Parker (9 December, p 1641), for many years I have pointed out that the symptoms of "exposure" and hypoglycaemia are virtually identical, and am basically in support of current trends in management, having practised them over many years. I have found several low blood sugar readings in 